\title{
Niedźwiedzia Przysługa? Bear's Favor? Hidden Garden behind the Concrete Proverbs: Cognitive-Semantic Analysis of Proverbs in Persian, Polish and Spanish
}

\author{
Rajdeep Singh \\ European Studies, Department of regional studies, University of Tehran, Tehran, Iran. \\ E-mail: rajdeepsm@gmail.com \\ Received: January 24, 2019 \\ Accepted: February 13, 2019 Online Published: March 1, 2019 \\ doi:10.5430/elr.v8n1p20 \\ URL: https://doi.org/10.5430/elr.v8n1p20
}

\begin{abstract}
Proverbs help us understand how the society works at large and what are the main concerns regarding the environment, people-to-people exchange and notions of liberty, freedom and values. In some cultures such as the Iranian one, the way one uses proverbs depends on the generation one finds herself in. Generation-gap provides opportunity to transfer some abstract and complicated concepts, not available in modern life, through the use of proverbs. From childhood, by hearing proverbs from parents and grand-parents, children begin grasping some important national and even religious concepts. In order to represent a rather international, holistic view and not language-specific, we analyzed further Polish, French and Spanish proverbs, whenever deemed necessary. The present paper through cognitive-semantic and content analysis aims to reveal the implied systems of value, ethics and morality realized through proverbs. The results clearly indicate that proverbs cover different systems of values through elements such as artifacts, animals, human body parts and even imaginary, nature-derived elements.
\end{abstract}

Keywords: Polish; Persian; Spanish; society; cognitive analysis; semantic analysis; proverbs

\section{Introduction}

As common Iranian wisdom puts forward, there's supposed to be a proverb for every occasion, here and there, no matter who is contributing, from teenagers to old folks. Browsing through the mind-boggling expanse of Iranian paraemiography, one can't help but feel the interesting fact that there seems to be always more than one available. More often than not, they actually bring about opposite views, contrasting different world-views of the same people. So is there anything like basic lexicon, common to the Iranian mind, extractable from these banal but powerful tools of proverbs, and if so what would be the consequences for language learning experience? These are some of the questions we tried to answer in this paper. We will look at the most popular, interesting and awkward Iranian proverbs. In reality, we will begin a journey to the old times to see how people in Persia began putting world in different categories and frameworks. We want to capture that inner processing that enabled the genius of language to categorize the world the way they felt. What do they say about Iranian cultural and historical reality? We all have some common understanding of the ways things work out in our life but how exactly do we put into words these realities? What happens when you translate them? And what you can learn from them? Because, as one Iranian proverb claims, 'weaving the sky and string together,' or aseman o risman ra beham baftan! Such proverbs is used to describe situations of opposing facts and non-coherent.

Nabifar (2013) analyzes the semantic meaning of proverbs in Persian and English, pointing out to the frequent use of animals in Persian proverbs and claims that "In general in analyzed Persian proverbs, animals are used more...Proverbs in both languages have the same functions and underlying the same deep structure and meaning...Proverbs are a great source to gain insight to the way mind conceptualizes the real world and experiences...proverbs extensively make use of animals as the source of metonymy (p.2301). Alas (2017) provide educators with a unique perspective on the teaching and emphasizes the value of proverbs in the learning experience pupils have in the classroom and for this, Alas draws outlines of the semantics and pragmatics of proverbs while explains the impact of such usage of proverbs on students living in a modern era and culture. Singh (2018) looks at the different aspects of interplay between cultural notions and their semantic hidden meanings. He describes situations where known religious words have lost their original meaning through a sophisticated mind processing. Singh (2018) also investigates the problems many learners face when they are in the process of learning languages 
which have a completely different phonetic structure and makes clear some of the probable mind processing which makes learning a foreign language more difficult.

Hallin and Van Lancker Sidtis (2015) investigate prosodic characteristics of proverbs since they are part of the larger formulaic expressions such as tonal patterns and rate and the results revealed that tonal pattern distributions were different between proverb sentences and control ones, pointing out a 'less stress' tonal pattern in proverbs, which may have been proverb-specific. Proverbs were spoken much faster and easier by the subjects, while showing a significantly faster rate in proverbs known to subjects and more variability in tonal patterns. They conclude that the results indicate that proverbs have distinctive prosodic characteristics compared to newly created language. One of the intriguing facts about the formulaic expressions is the way it can affect people with mental issues such as Parkinson. The production of formulaic expressions is considered to be excessive in the left hemisphere and deficient in the right hemisphere and even in sub-cortical region. Persons with Parkinson's disease (PD), having dysfunctional basal ganglia, are predicted to have problems with formulaic expressions, showing impoverished formulaic expressions in contrast to speakers with other mental issues such as ones with Alzheimer's disease. Van Lancker Sidtis, Choi, Alken and Sidtis (2015) conduct an interesting study about such correlations between mental diseases and use of formulaic expressions where they compare participants with Parkinson's disease and Alzheimer's disease and then probing production and comprehension of formulaic expressions. They note that "results are compatible with a view of defective storage and comprehension of formulaic expressions in association with cortical dementia but not sub-cortical impairment" (p. 1501). Further they claim that the results showed that "Participants with PD performed worse than the $\mathrm{HC}$ participants on the spontaneous elicitation task but not on the utterance completion task or other tasks of formulaic language recognition or comprehension" (p.1501).

Gibbs, Colston and Johnson (1996) investigate the way proverbs have been treated to get an idea about the metaphorical mind and the psychology behind it. They argue that they acknowledge the contributions made in comparing psycho-linguistic evidence against cognitive linguistic analyses of proverbs and the mismatch between these two fields. However, they point out that psycholinguists did not take into consideration the goals and methods of cognitive linguistics and assumptions made in this field. Overall, it is important to consider cognitive linguistics as a research area where the goal is to discover much more abstract notions than in the psycho-linguistics.

Earlier attempts at Cognitive Linguistic inroads into the paremiologist's domain experienced some harsh resistance and even criticism regarding the incompatibility of the two fields. However, many have tried to reanalyze the potential of such cross-fertilization and harmony of solutions. Bulijan and Gradečak-Erdelić (2013) with this goal in mind analyze a selection of English and Croatian proverbs from a cognitive linguistic point-of-view, showing that this endeavor can yield a win-win situation for both sides of the argument. They claim that "The quest for universality/shared conceptual motivation typical of Cognitive Linguistics does not need to detract from the paremiologist's folkloristic concerns. In fact, we propose cognitive linguistics as the framework for an integrated approach to studying both the universal and the culture-specific in proverbs"(p. 63). Khatri and Laishram (2013) investigate the cultural embeddedness of the proverbs from Manipur, a small state in North-East India. They consider and analyze various aspects of the Manipuri culture through the handful of proverbs, trying to understand the cognitive foundation of the proverbs being used. In this, they analyze how barrel, basket and pond are the containers, metaphorically representing the society as a container which is different to many other cultures. Khatri and Laishram (2013) claim that "rice, apple, mango and fish are content representing an individual in the society...Single spoiled content is harmful for the contents in the container... from the perspective of society, the spoiled individual is harmful for the reputation of the society" (p. 4).

There are some folklorists and proverb scholars who see proverbs as the essence of a nation. They claim that proverbs are the genre that best keeps and preserves, represents and depicts the common and typical character of a nation, regardless of similar concepts in other nations. There are, however, many scholars from cognitive field who maintain the more modern and holistic view that proverbs tend to overpass all the national, human made boundaries. These latter scholars corroborate their stance by mentioning numerous international proverbs which happen to be available nowadays abundantly. We are also inclined to consider a rather universal way of packaging the world around us, no matter which nation one belongs.

In this study, we brought together some of the most important proverbs in Persian and then analyzed them to see which are the main basic concepts that Iranians have considered routine and important throughout their history. In fact, we claim that there are lexical categories that are closest to Iranian thinking and they form the basic schemata to build other words and meanings. Basic lexicon refers to the first conceptualized notions. People look around and pay attention to different aspects of life and nature. Then they begin conceptualizing whatever is in their focus of 
attention. What we tried to do in this work was to find most basic concepts that people apprehend from their immediate environment.

Proverbs have been explored from perspective of a wide range of disciplines and there have been many studies which concentrate on the multi-disciplinary approach to proverbs. These include anthropology, history, linguistics and literature, among others. From the linguistic perspective, many abstract meanings are hard to be accessed directly. Therefore language makes it possible to have access to them through more direct and basic notions. Proverbs are one of the easiest tools to deal with this. Notions such as value, love, happiness and many such abstract ideas are realized by the use of basic concepts. Unlike earlier studies that have analyzed proverbs from the point of view of speech acts, the present article draws on the more recent breakthrough in the proverb analysis and uses perspective of cognitive meaning and symbolism. Most importantly, it is shown that the proverbs are sensitive to cultural values and context in which they produced. Through proverbs, the speakers exchange different notions and they also commit themselves to pragmatic acts which such as advice, accuse, pronounce, threaten, etc. The proverbial propositions are reformulated in their original meaning as well to unveil their meanings, allowing readers, regardless of being members of the culture, to fully access the notions. We begin analyzing them one by one and then we propose different schematic meanings of core concepts in proverbs.

\section{Values}

Our values shape who we are, what we do and how we feel about the world surrounding. Our norms, too, form and introduce the way we are ought to act, feel, interact and speak. Without norms, many interactions would simply fail. Values and norms form the framework under which we begin analyzing the things that we deem appropriate. Since it seems neither practical nor desirable to remove our lives from values and norms, an important question arises as to how do we truly put into framework all this aforementioned value-norm system into spoken strings? These values, being subjective in essence, can be common among nations? When we analyze proverbs, we are faced with an interesting reality, which expresses the common essence of human experience, in the most subjective area of life, namely the system of value and norms. Proverbs are windows to discover this hidden common value-system which sometimes has been analyzed unfer the framework of aesthetics and the practical sciences. Morality and value system have been forming a range of symbolic and meaningful concepts in the society. Therefore, there are many proverbs which concentrate on the notion of value and ethics. In the following proverbs, different notions of value and morality are realized, vocally, through the use of proverbs. For the readers, we have developed the schematic illustration of the conceptualization, and we also have provided the literal meaning for those who are not familiar with Persian, Polish, French, and Spanish.
A1) Pool
alaf
$\mathrm{e}$
khers
nist.
Money grass of bear
is not. (Money is not the bear grass)

A2) Il ne faut pas jeter les perles devant les pourceaux

Do not cost your pearls before swine

A3) Cada uno sabe dónde le aprieta el zapato

Each one knows where his shoe is too tight

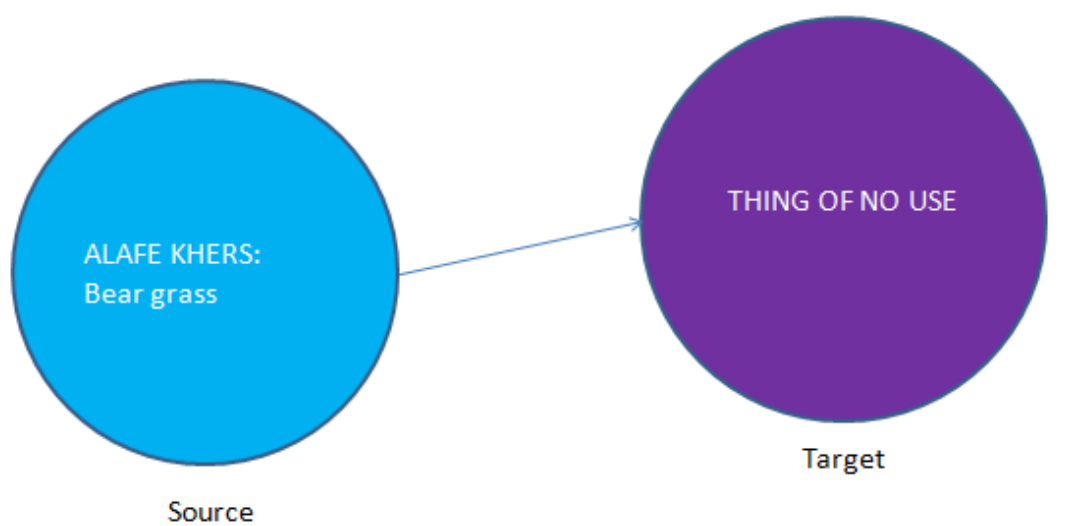

Figure 1. Source and target in A1 (Persian) 


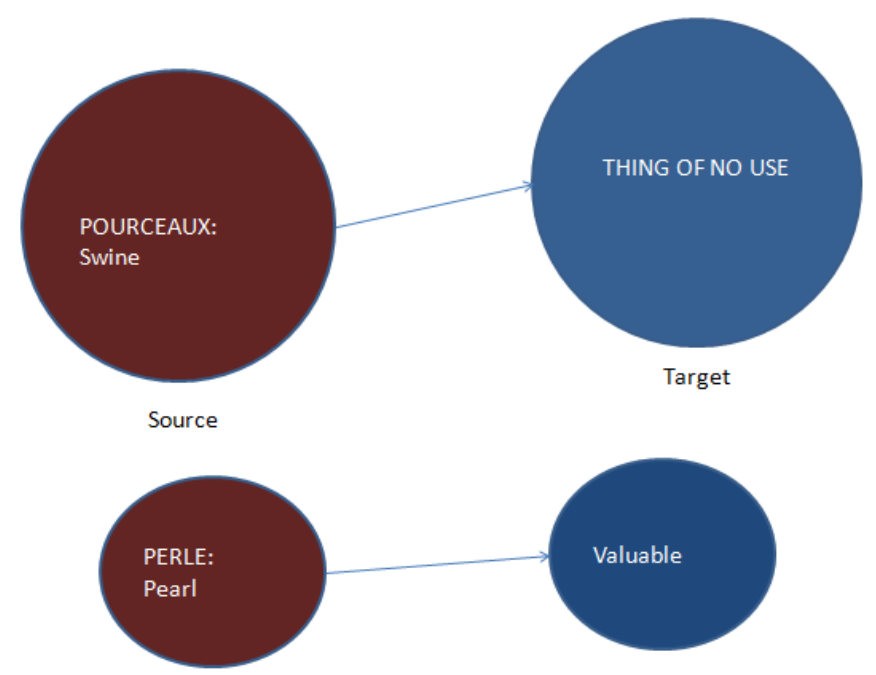

Figure 2. Source to target in A2 (French)

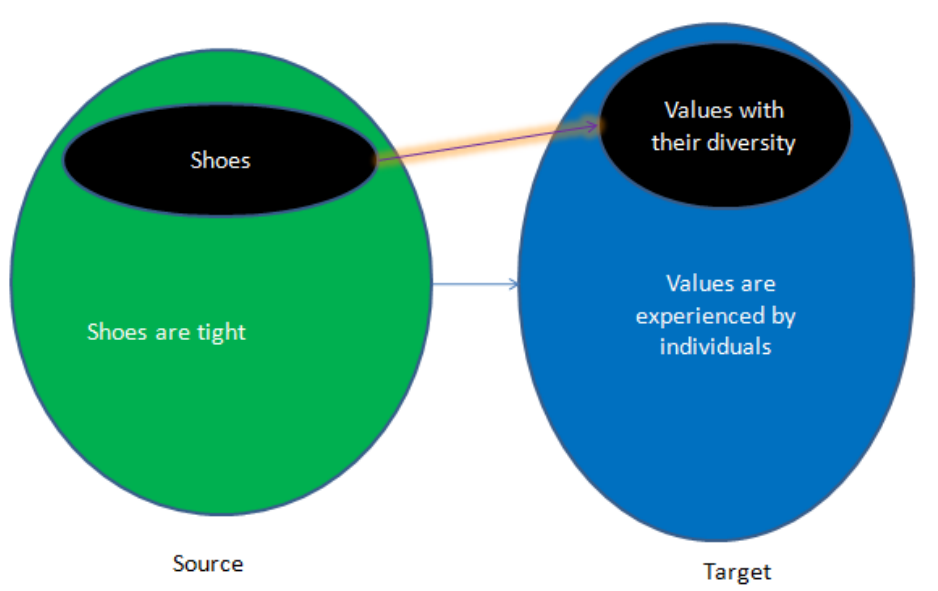

Figure 3. Source to target in A3 (Spanish)

\subsection{Uniformity}

Idea of uniformity overlooks, in many ways, the strong influence of divergent feelings and judgments about common concepts, just as there was a pervading influence of different currents of thoughts in countries where there have always been racial and social diversity. This conflict of undercurrent flow of values has been exercising influence on the small scale, in the villages and small urban areas. Any idea of global uniformity, therefore, deemed to be a failing attempt to see the world, in a way which is not true. Many think it simply to take into account that many of the cultural norms that are prevalent in the modern society have been grown out of local values and they turn out to be of culturally mixed origin. However, there are many indications in proverbs to uniformity as a prevalent practice in the society. In the following examples, we try to cast some light on the way the conceptualization of uniformity was done in different cultures.

B1) kabootar ba kabootar, ghaz ba ghaz.

Dove with dove, goose with goose. (dove flies with dove, and goose with goose)

B2) birds of a feather flock together.

B3) qui se ressemble, s'assemble.

those who look similar, stay together 


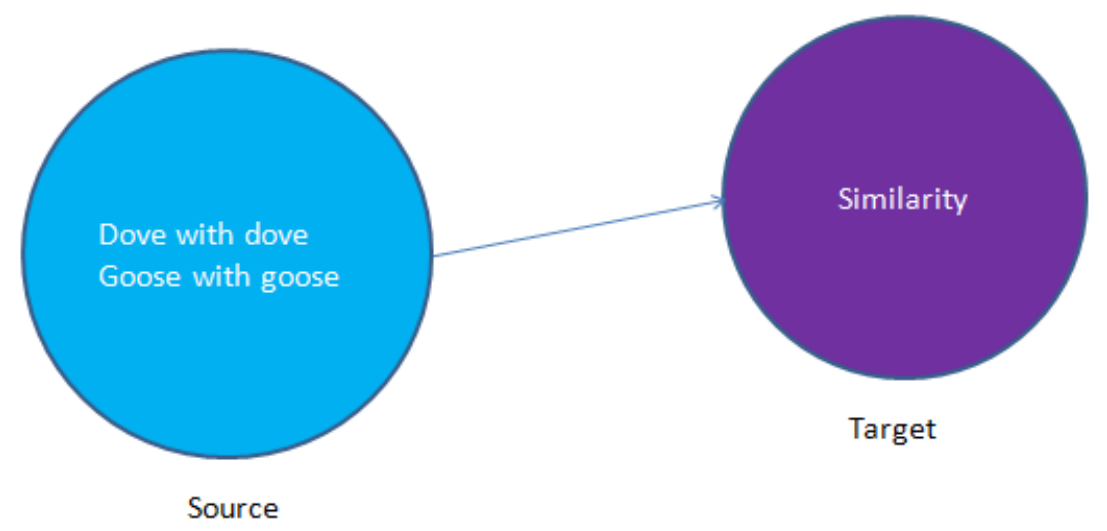

Figure 4. Source and target in B1 (Persian)

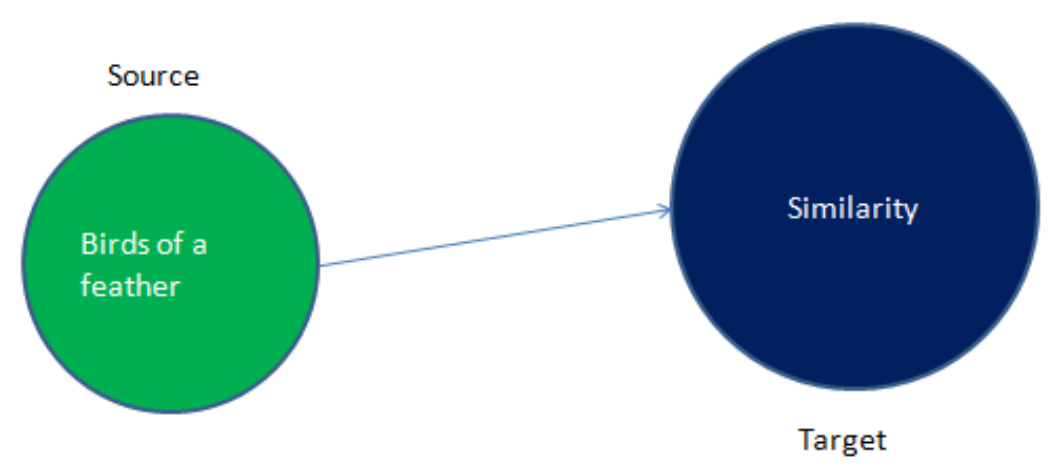

Figure 5. Source and target in B2 (English)

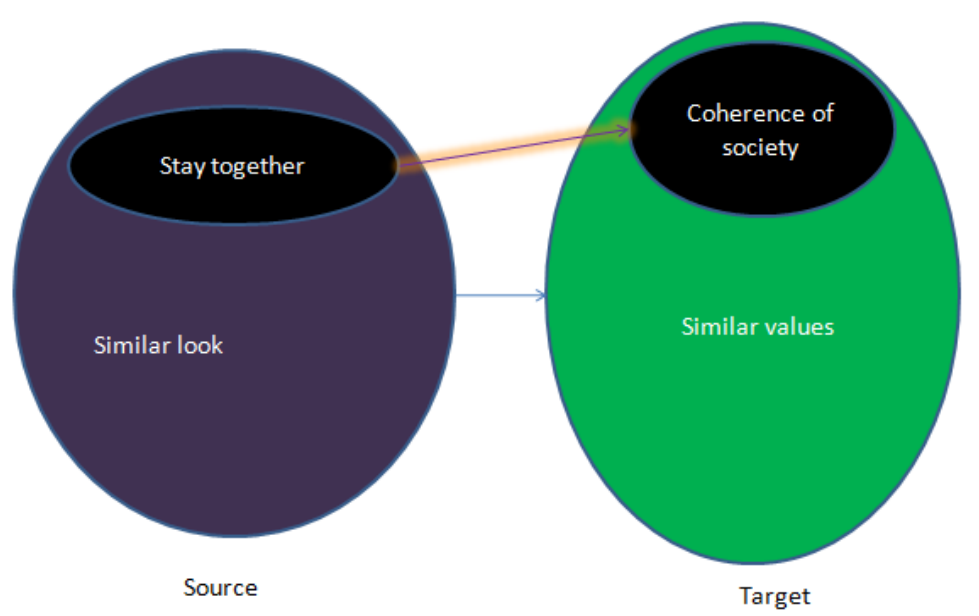

Figure 6. Source to target in B3 (French) 
C1) Khahi nakhahi rosva, hamrange jamaat sho.

If you do not want to be ashamed, adjust yourself to others (take their color).

C2) ALAF BAYAD BE DAHANE

BOZI SHIRIN BIYAD.

Grass should to mouth of goat sweet be (goat should like the taste of grass, not others).

C3) No se hizo la miel para la boca del asno.

Honey wasn't made for the mouth of a donkey.

C4) Kiedy wejdziesz między wrony musisz krakać tak jak one.

When you walk between the crows, you must croak like them.

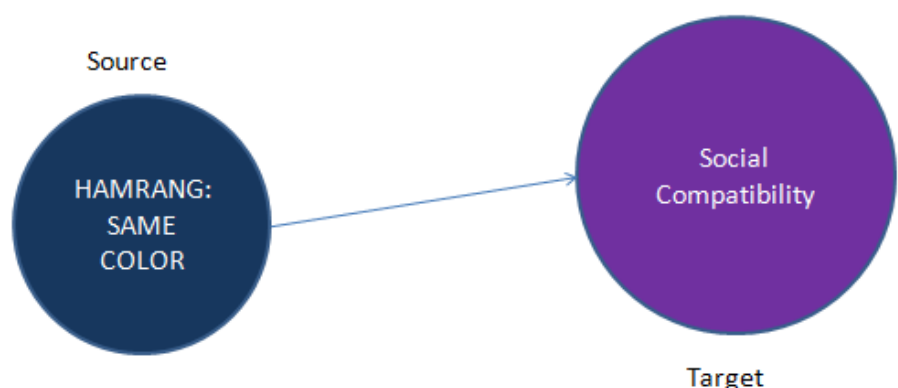

Figure 7. Source to target in C1 (Persian)

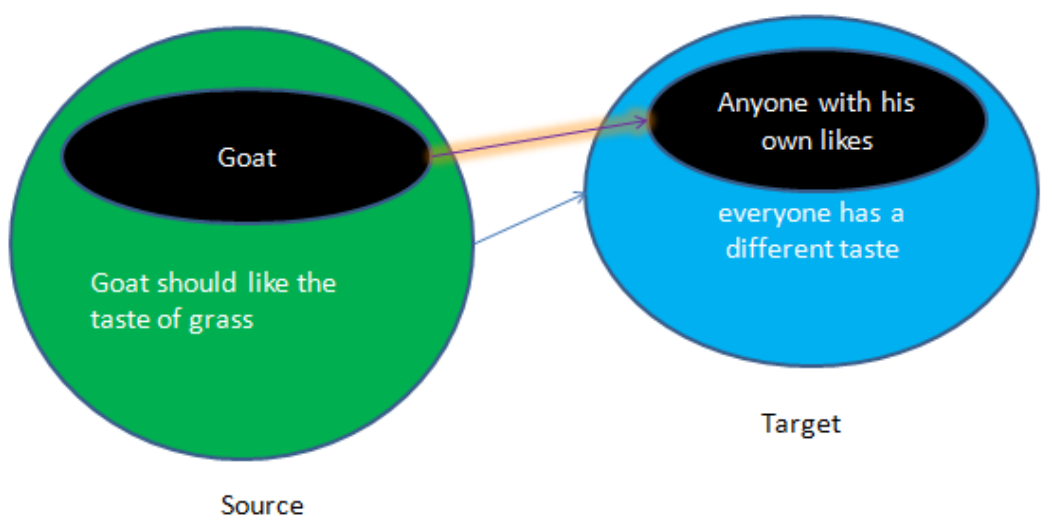

Figure 8. Source to target in C2 (Persian)

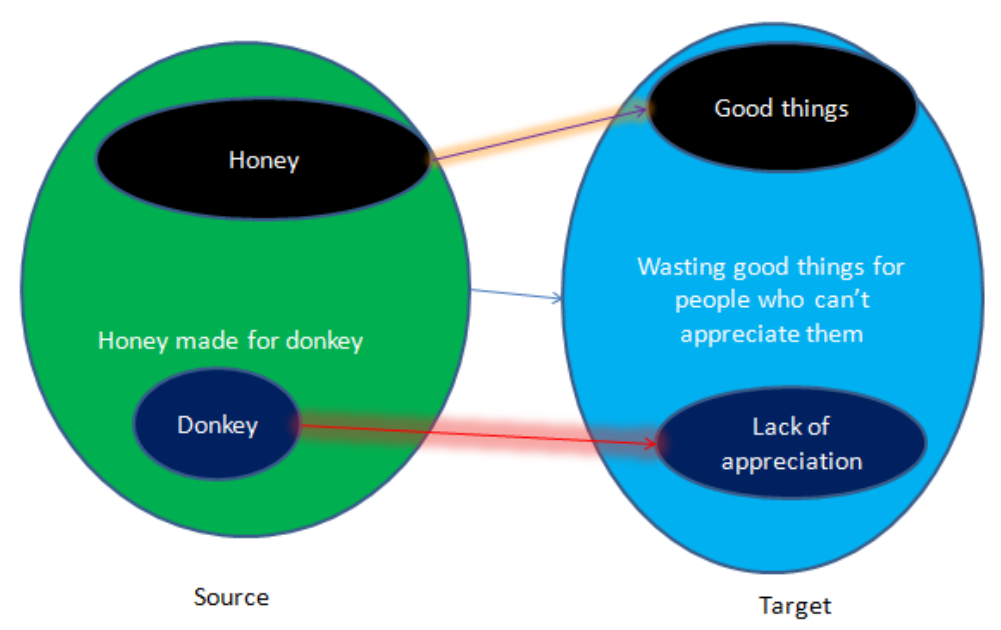

Figure 9. Source to target in C3 (Spanish) 


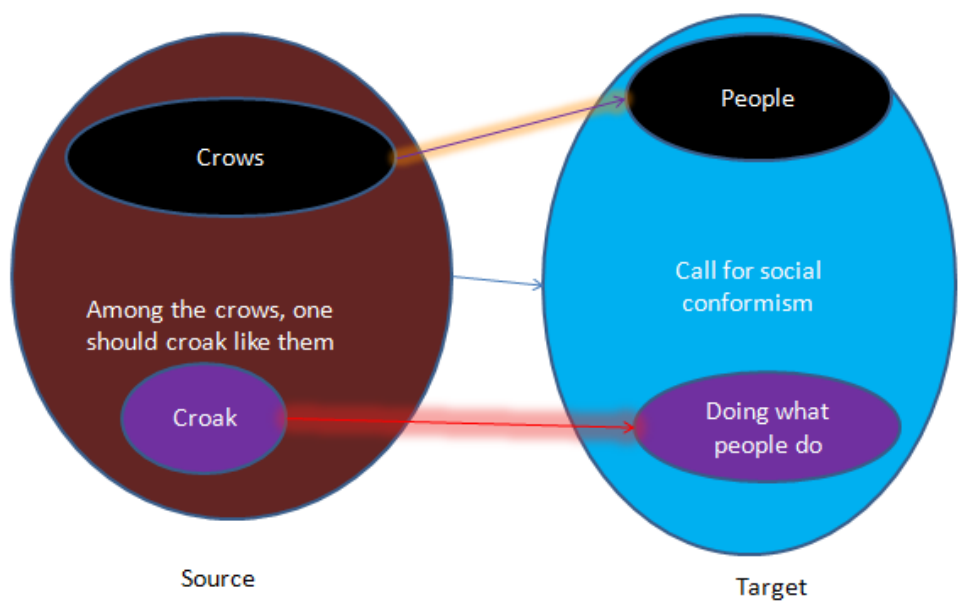

Figure 10. Source to target in C4 (Polish)

\subsection{Cooperation}

Many important social problems of mankind-from the environmental pollution to cultural interaction and conflicts - involve the principle of cooperation between people who are socially unrelated or at best socially diverse. Harmony in society is not given and individual self-interest is a driving force that resists any attempt to become harmonized for the benefit of others. However, in proverbs, we find many instances of encouragement for a wider cooperation and this proves that considering individuals as ones who pursue their own benefit alone is not realistic and too pessimistic and much more cooperation exists that is not easily compatible with the egocentric assumption. have shown that this prediction is way too pessimistic and that much more cooperation exists than is easily compatible with the selfishness assumption. Persian culture sees the cooperation as an important part of its value system. In the following example, body parts are actually used as a metaphoric shell, instantiating much deeper concept of cooperation. This is not restricted to Persian since polish language and culture also make extensive use of body parts for metaphorically substantiating the cooperation concept. The next approach is to go beyond the micro-level analysis and ask whether there are differences in cooperation behavior across cultural backgrounds; with which we mean across a set of diverse values and beliefs that the majority of people in those societies hold and transmit them from one generation to the next. From our analysis, there are common but also contradictory cultural core which indicates implicitly that world-views are formed in their own cultural background. The following examples cast some light on the notion of cooperation and the cognitive processing necessary to put this concept into strings of words.

D1) yek dast seda nadare

One hand voice doesn't have. (One hand doesn't clap)

D2) Ręka rękę myje, noga nogę wspiera

Hand washes hand, leg supports leg. 


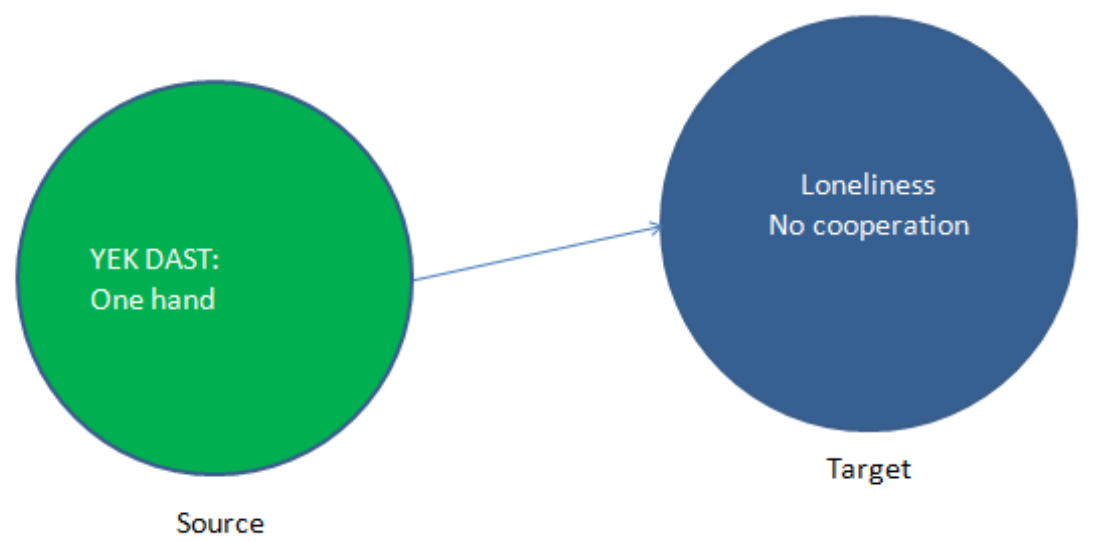

Figure11. Source and target in D1 (Persian)

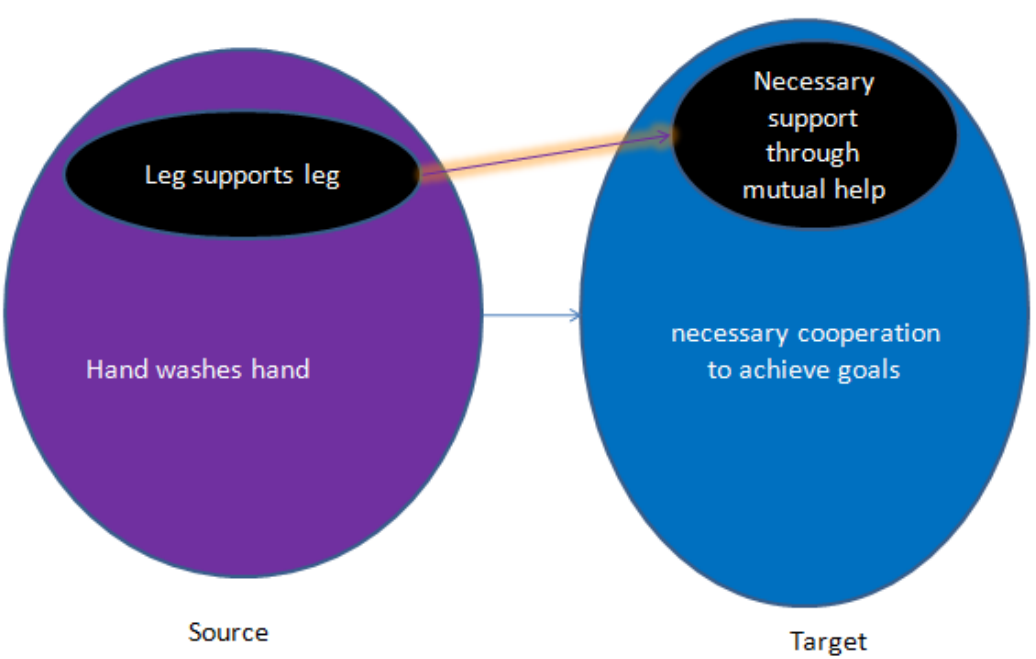

Figure 12. Source to target in D2 (Polish)

\section{Fear and Hope}

The present world is characterized by the spread of fear and all of the risk-related notions we hear on a daily basis. This whole atmosphere can be called the "culture of fear" This fear is the core stumbling block to a culture of hope and it seems that this internal contradiction is central to culture from perspective of different social points of view. But the nature of fear is not constant and it varies as societies are maturing and changing elements in their system of values. There seems to be a changing environment for the growth of hope and comfort in the society. Different cultures shape varying backgrounds for their conceptualization of hope which entails that proverbs, as a strong inter-generation communication tool, play a deciding role in depicting the inexorable social, moral and environmental adversities in the shape of fear and opportunities in the form of hope. In the following examples the semantic-cognitive meaning of the proverbs carrying the notion of hope and comfort are further analyzed.

E1) ab az ab takan nakhordan

Water from water moved not (There is no agitation in the water).

E2) ab az asyab oftadan

Water from mill fall (there calm reigns).

E3) Harkas be omide hamsaye neshinad, gorosne mikhabad.

Whoever to hope of neighbor sits, hungry will sleep (Whoever hopes a favor from the neighbor, 
will sleep hungry at night).

E4) Nadzieja matką głupich

Hope is the mother of the stupid

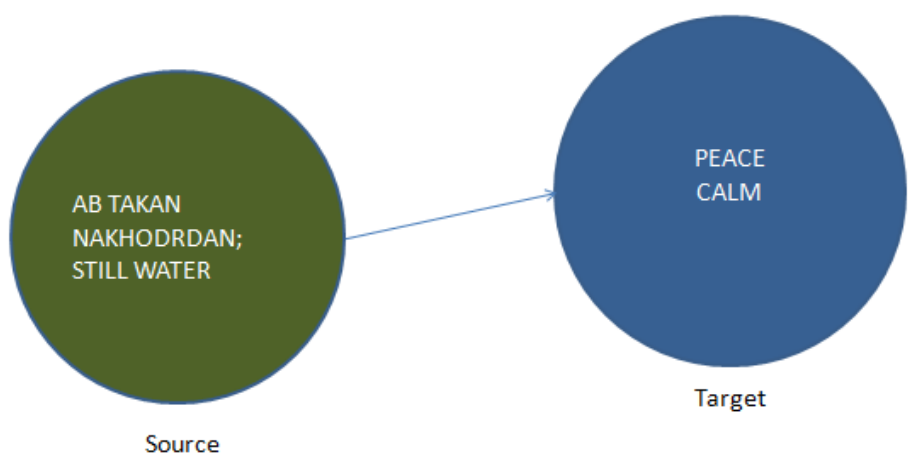

Figure 13. Source to target in E1 (Persian)

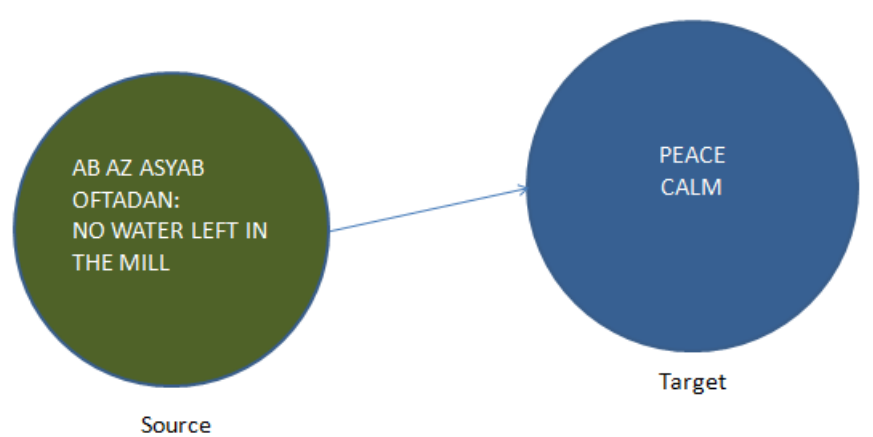

Figure 14. Source to target in E2 (Persian)

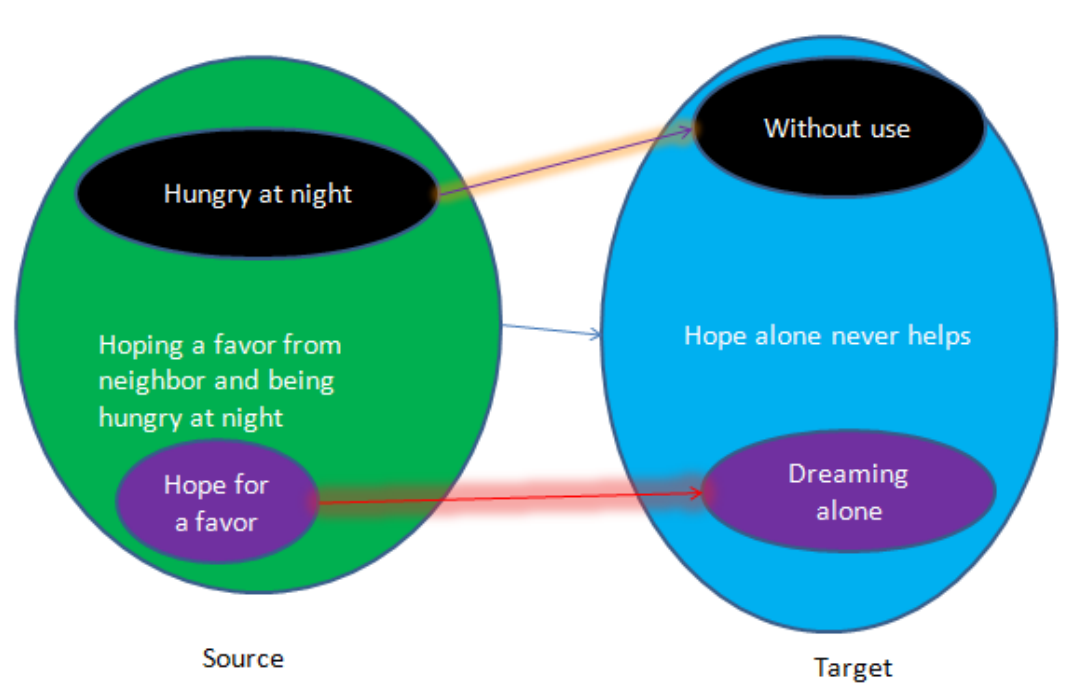

Figure 15. Source to target in E3 (Persian) 


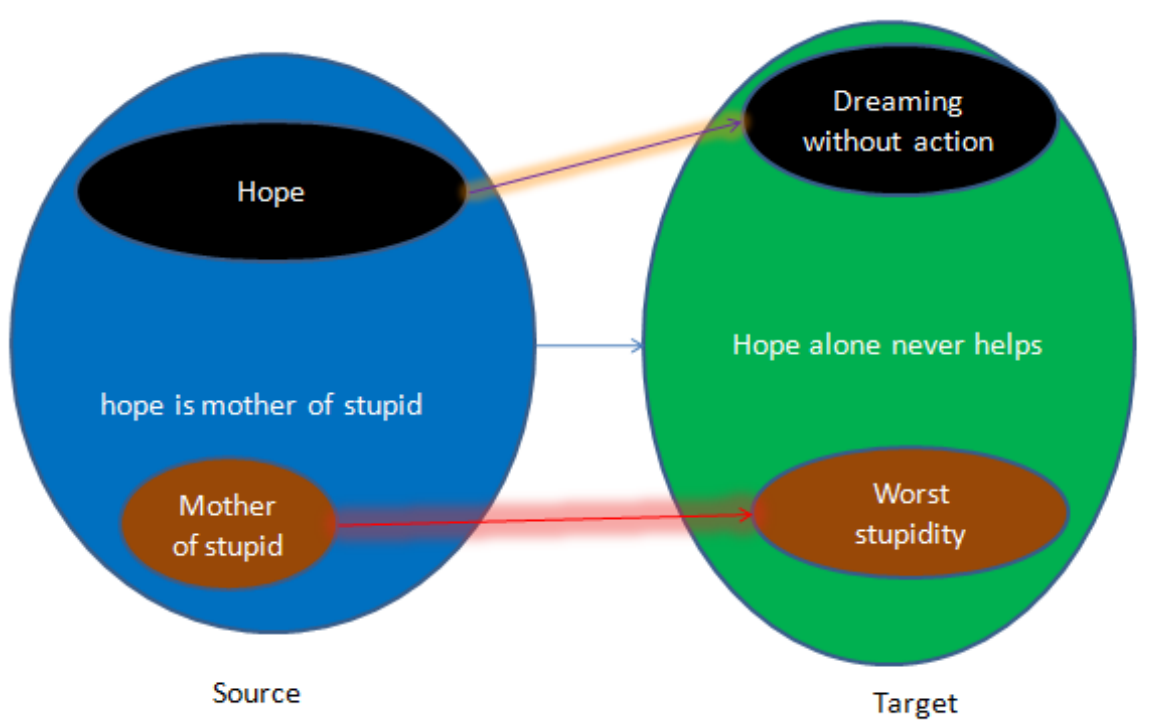

Figure 16. Source to target in E4 (Polish)

\section{Ethics and Morality}

The ethics in Iranian society has always been linked and embedded in what is wrong or right and ways to characterize the differences between good and bad; it is also linked to what is acceptable as a social act, put within the social context and the division between private and public spheres. In fact, the public/private division is even characterized by many proverbs in a general way, regardless of which language people happen to speak. Furthermore, the socially appropriate conduct is embedded in the patterns of behavior which begets living through cooperation, preponderance of justice and respecting individual freedom and social diversity. In the following examples, different proverbs point out to different aspects of the ethics in Iranian society. On the contrary, we find some proverbs like the polish one which advocates the morality of collecting wealth individually.

F1) Atash chon barafrookht, besoozad tar o khoshk.

Fire when is set up, burn wet and dry (when there is sin, everyone, the whole society, will get punished, no matter who has sinned).

F2) Azmoode ra azmoon khata ast

once tried to test wrong is (Testing what has already been tested once is wrong).

F3) Od przybytku głowa nie boli.

You can't get a headache from abundance.

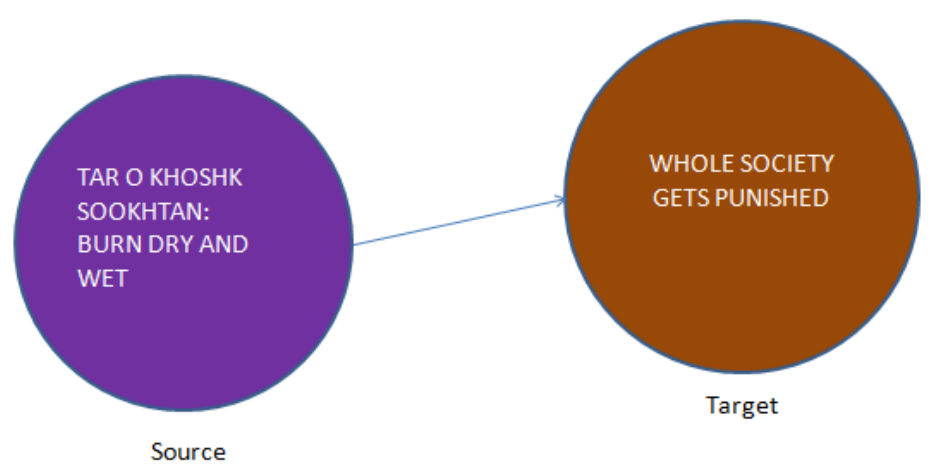

Figure 17. Source and target in F1 (Persian) 


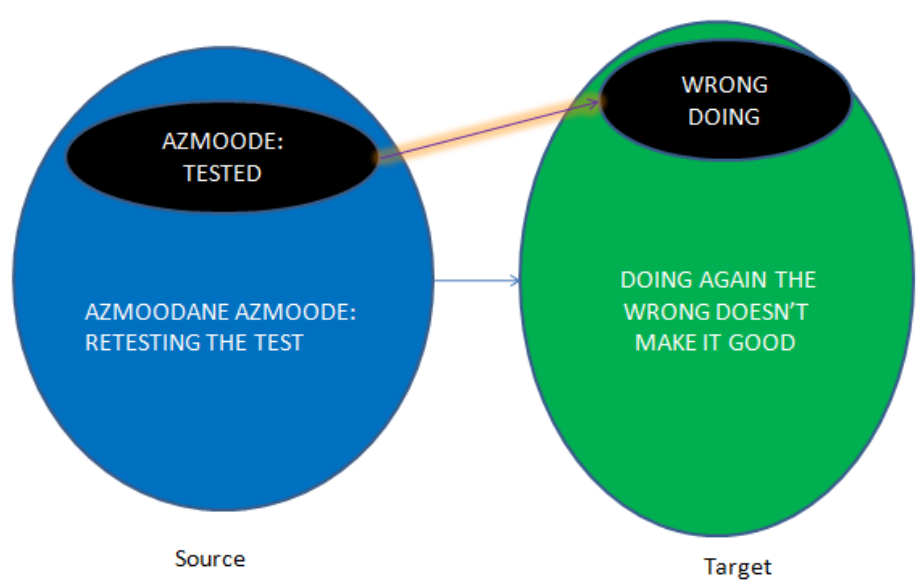

Figure 18. Source and target in F2 (Persian)

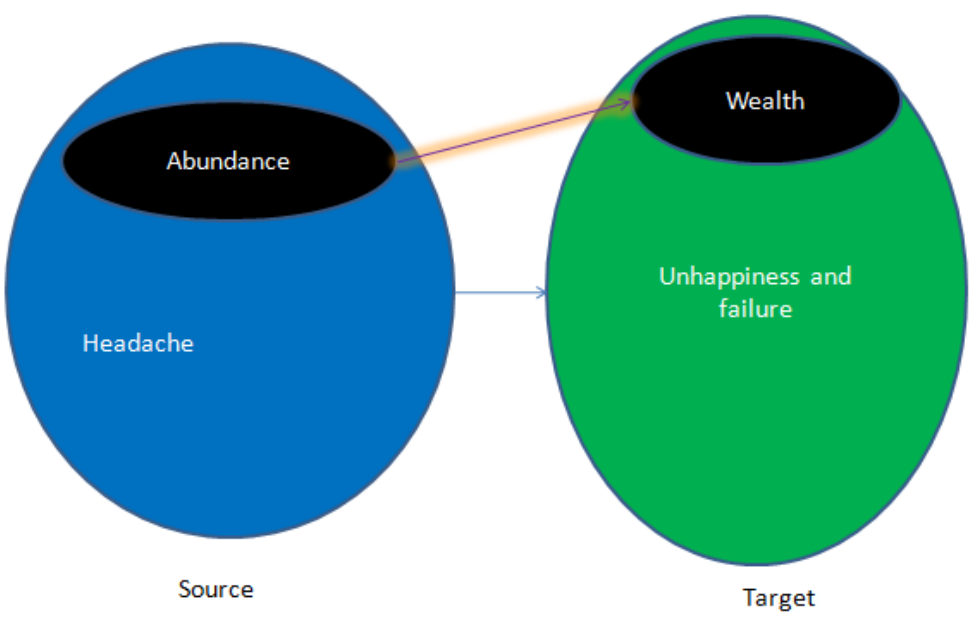

Figure 19. Source to target in F3 (Polish)

\section{Advice and Guidance}

Iranian lifestyle has interesting generation-specific cultural norms. In the sense that what is appropriate for a grandma may not work out for her granddaughter. On the other hand, the common way of life for Iranians has a certain mingling character known to happen between family members of different generations. This kind of lifestyle that children grow up in and the culture where parents or grandparents grew up can be a rich and fulfilling experience - even though there are times when conflicts and challenges begin to emerge. When approaching to the rich heritage and historical essence packaged in proverbs, it can be difficult to balance these different generation-specific lifestyles and matters concerning historical realities. Simple things like food through to language show just how complex this can be and that's why proverbs are such a great tool to go back and look around how past generations found appropriate proverbs as tools to advise younger generations about some dos and don'ts.

Living, studying and working, for sure form and shape some of beliefs and values people enshrine in the close family circle. However for younger generations, there are countless other factors contributing to our belief systems and everyday way of life and good advice from grandparents, in the guise of proverbs, have been playing an important role in the Iranian psyche. In the following examples, we analyze the cognitive-semantic meaning of some of the famous Persian and Polish proverbs.

G1) Chahkan hamishe tah e chah hast

Digger always bottom of pit is (pit digger will be at the bottom of pit himself). 
G2) Kto pod kim dołki kopie, ten sam w niewpada.

He who digs pits for others will fall in them himself.

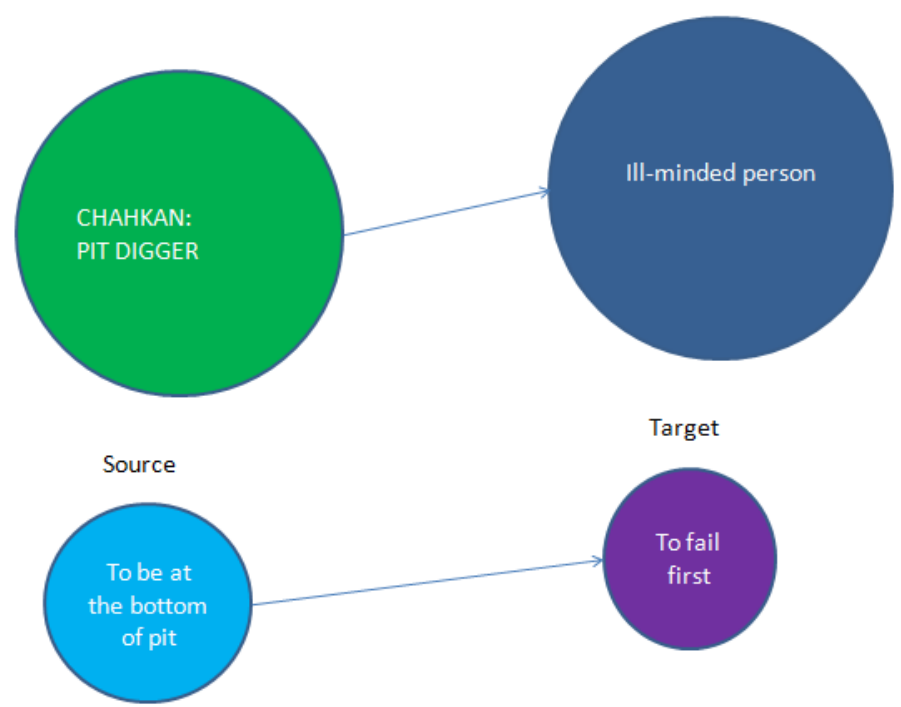

Figure 20. Source and target in G1 (Persian)

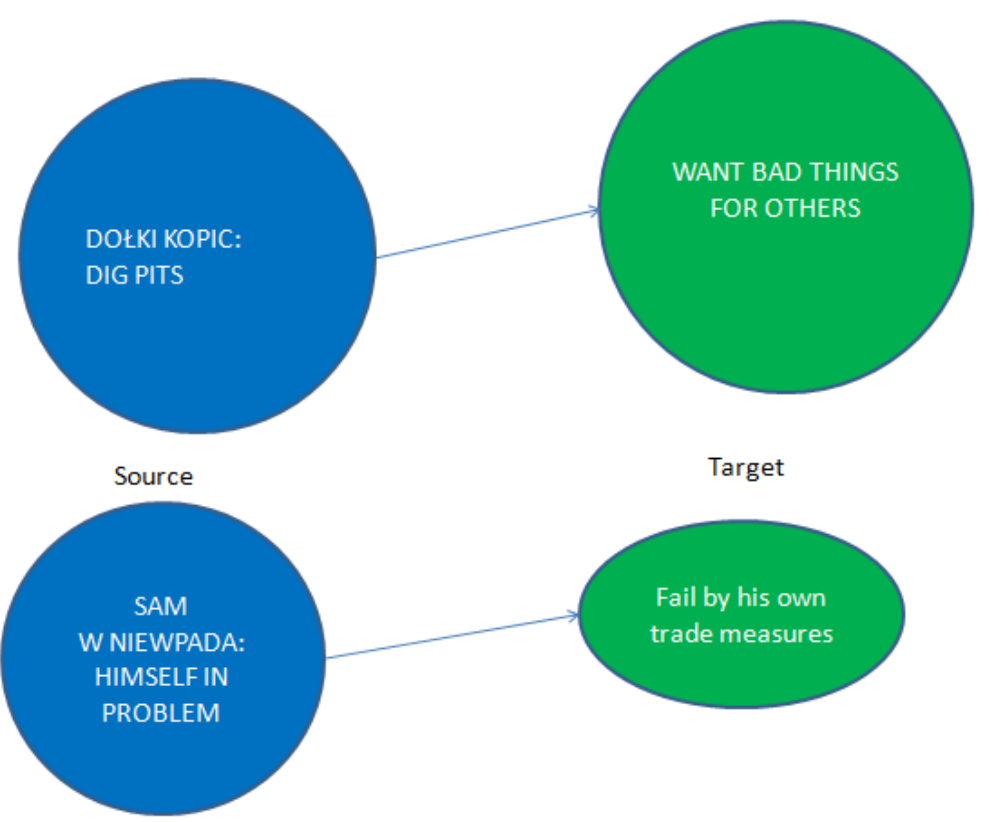

Figure 21. Source and target in G2 (Polish)

\section{Contentment}

Different cultures appreciate different lifestyles. However, Contentment is regarded as an important aspect of many cultures. It is interesting that Eastern and Western cultures as different as Iranian and Spanish ones have come up almost with the same notion, though in different wordings. Apparently, many feel they possess adequate amounts of income, good health, trusted friends, and that they consider themselves to be able to be generous, and lead their lives the way they like. But does that make them "happy"? It's not unusual to meet many miserable people who have an abundance of these things while there are many relatively poor people whose lives are full of adversity and problems, 
but they seem to have a positive outlook on life.

In Iranian culture, being able to enjoy decent income, good health, trusted friends, an ability to be generous, and integrity among my leaders are considered to be related to the concept of contentment or "Ghanaat" in Persian. However, in European culture, we still find people who desire the same thing, that inner peace. This inner peace comes from emotions that are satisfied not with material things, but rather with psychological notions and thoughts. The next examples illustrate the conceptualization of contentment across different languages.

H1) Kachi behtar az hichi hast.

Keachi (type of spice) better than nothing is (something is better than nothing).

H2) A falta de pan, buenas son (las) tortas.

In the absence of bread, cakes are good.

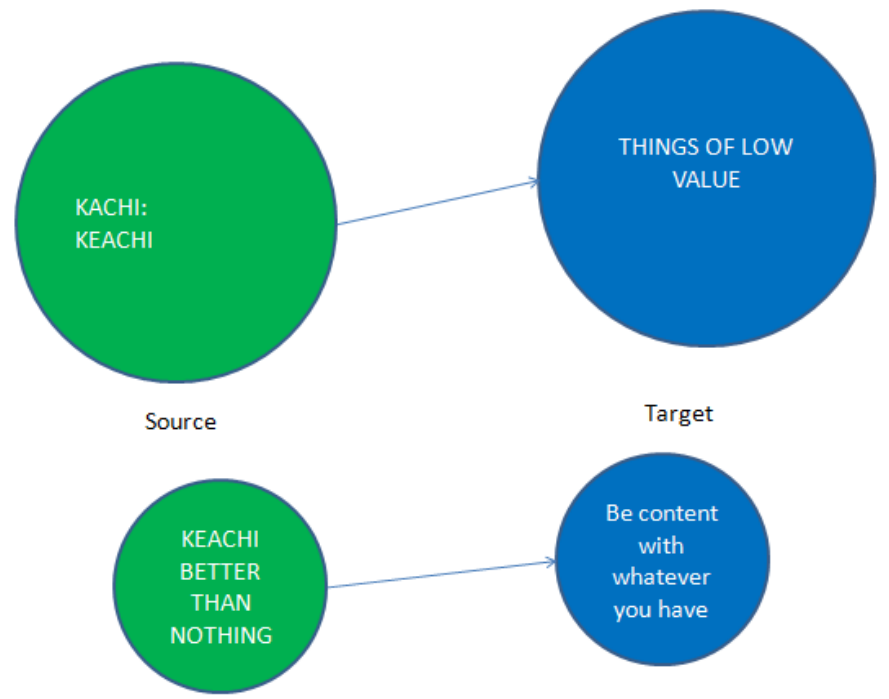

Figure 22. Source and target in H1 (Persian)

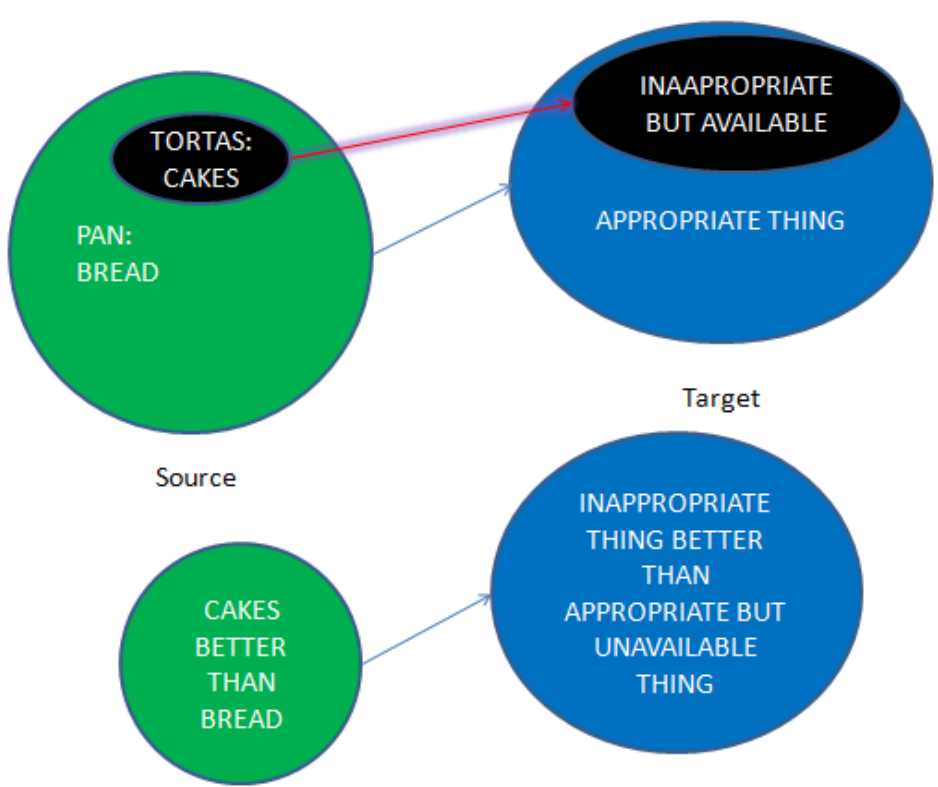

Figure 23. Source and target in H2 (Spanish) 


\section{Planned and Timely Task}

Our life is about goals. It's hard to find people who live on a daily basis without any clear goal in their mind and somehow rare person lives without an ultimate aim or a dream bird fluttering somewhere over a horizon. However, reaching this goal is always complicated and different cultures use different ways to pinpoint this important notion: planned task. This implies performing thousands of petty tasks and here and there insignificant things, everyday chores, meetings and actions. Planning these activities effectively is what time management is about. Time management and overall appropriate and managed tasks are notions common to many cultures including Persian and Polish. The following examples illustrate how planned tasks are realized in words in Polish and Persian.

i1) Nie dziel skóry na niedźwiedziu.

Do not divide the skin when it is still on the bear (don't count your chickens before they're hatched).

i2) niedźwiedzia przysługa

Bear's favor (A favor which ends up being worse than was worth it).

i3) jooje ra akhare payeez mishemarand.

Chickens end of autumn count (don't count your chickens before autumn).

i4) doostiye khale kherse

Friendship of aunt bear (A favor which ends up being worse than was worth it).

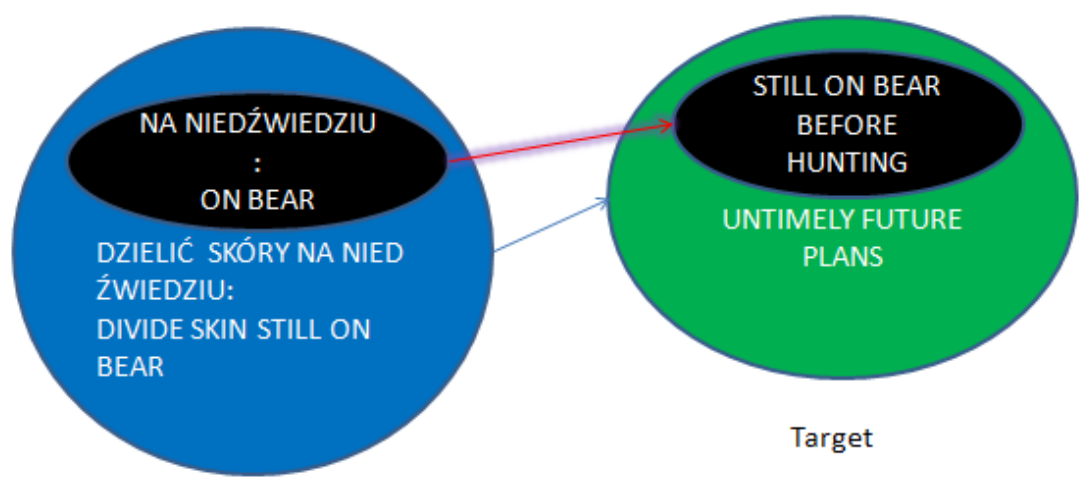

Source

Figure 24. Source and target in i1 (Polish)

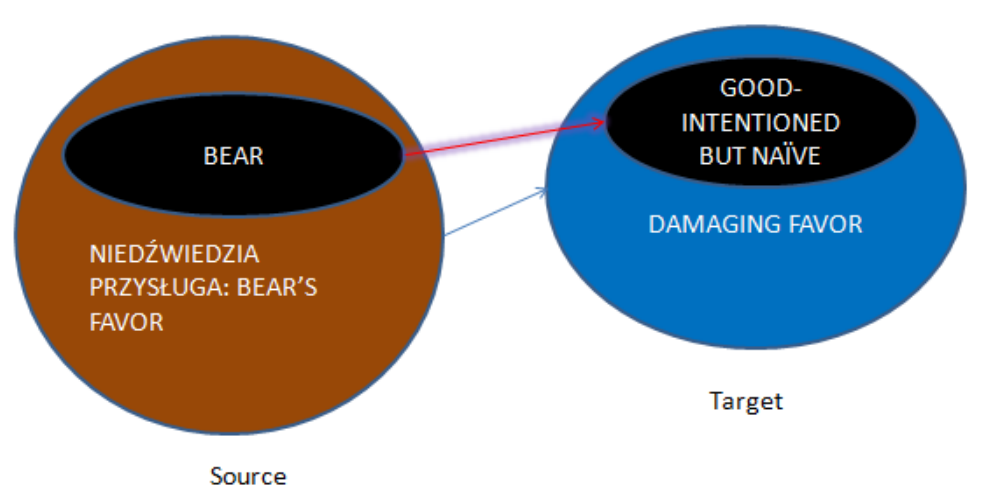

Figure 25. Source and target in i2 (Polish) 


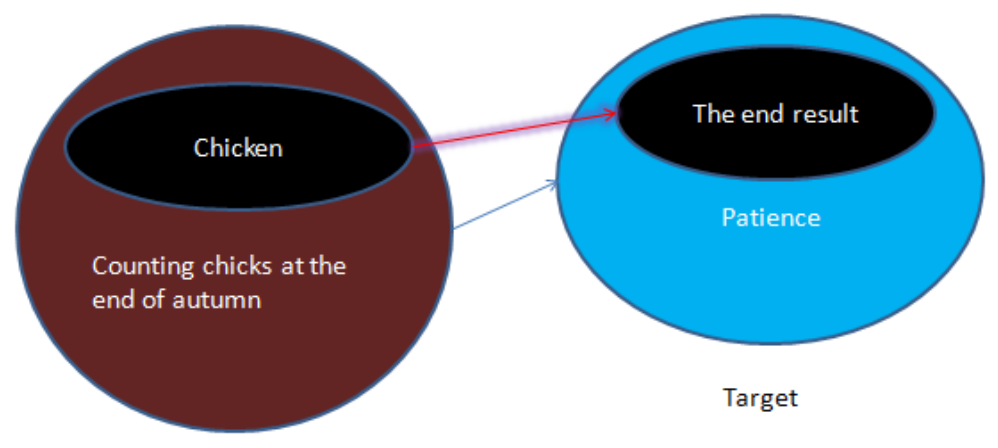

Source

Figure 26. Source and target in i3 (Persian)

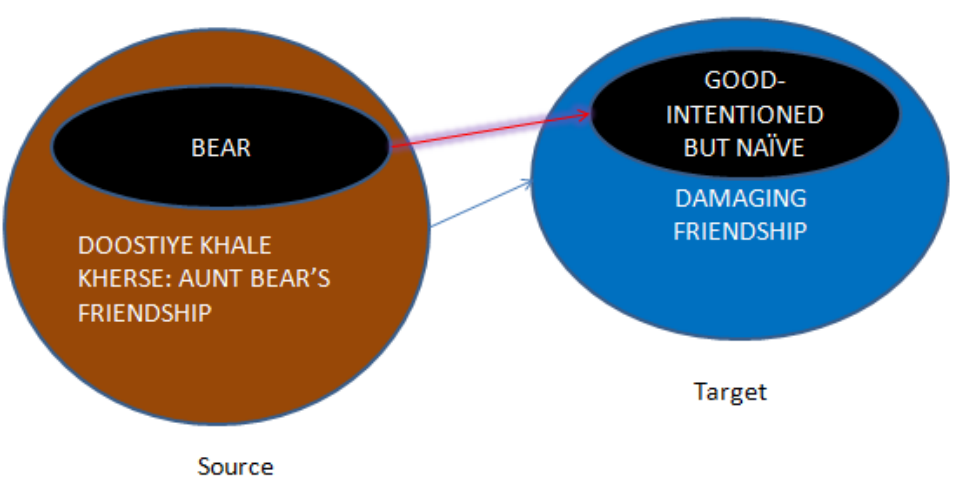

Figure 27. Source and target in i4 (Persian)

\section{Conclusion and Discussion}

A central tenant in this study was to explore the cognitive meaning behind proverbs in Persian, Polish and other languages as to gain knowledge of how people conceptualize the immediate environment with which they interact. In this, the symbolic and socio-cultural significance of selected Persian proverbs were analyzed and then compared to Polish and Spanish proverbs in the same system of values. Proverbs helps building a system of values and concepts which have the role of facilitator in communication as well as the transmitter of special messages of the cultural values of the people. The presentation of the proverbs in their original context-bound forms and their cognitive interpretations and meanings in Persian, Polish, Spanish and English puts an emphasis on the universal spectrum of the concepts symbolized in the guise of proverbs. Proverbs are windows to the past, they cover many items used in daily life, which are considered old-fashion by the new generation. Proverbs are like melodies that sing "Look for the morrow, the lost glow... the empty rooms, the cold blooms...the peeling paint, amazing restraint... the weathered floorboards, the broken chords ....all the voices, so distant, so faint...the broken windows, the betokened arrow...the broken heart, the unspoken start...the open doors, the torturing sore"(Singh, poem, 2018).

Proverbs are beautiful relics of the past and their significance cannot be over-emphasized. The use of symbolism in the daily lives of the Iranians, Polish and Indians, in creating different proverbs for treating unaccustomed situations is a very old practice that can be traced to antiquity. These symbols were formed in different shapes and are best represented through proverbs and other wise sayings. The history of the lives of the people are full of symbolism, incorporating hate and fate and whatever one feels waiting for in life to hide secrets and facts that are open to the heart and eyes of the community or society and also to transfer past experiences to the younger generation. The people, regardless of their origin, therefore, placed much value in these proverbs by novel hidden symbols which are to be explored; all activities in their daily lives are dealt with proverbs to create meanings, one that are more accessible to the younger generation and people around them. There are so many hidden messages in the heart of proverbs that needs to be explored by cognitive linguists, so that a more universal meaning can be found. With the 
aims of analyzing the messages and ways people conceptualize the environment, in our modern time, there is the need to delve into the conceptual analysis of proverbs, sayings and stories. These latter symbolize the world into beautiful, weighted pieces of concise sayings, left for the next generations to enjoy their originality and freshness.

\section{References}

Alas, Y. (2017). Environmental Awareness Education through Proverbs in Brunei Darussalam. SOSIOHUMANIKA: Jurnal Pendidikan Sains Sosial dan Kemanusiaan, 10(2). Retrieved from: http://www.journals.mindamas.com/index.php/sosiohumanika/article/view/916/826

Bulijan, G., \& Gradečak-Erdelić, T. (2013). Where cognitive linguistics meets paremiology: a cognitive-contrastive view of selected English and Croatian proverbs. Explorations in English Language and Linguistics, 1, 63-83. Retrieved from: https://hrcak.srce.hr/file/173903

Gibbs Jr, R., W., Colston, H., L. \& Johnson, M., D. (1996). Proverbs and the Metaphorical Mind. Metaphor and Symbolic Activity, 11, 207-16. https://doi.org/10.1207/s15327868ms1103_3

Hallin, A. E., \& Van Lancker Sidtis, D. (2015). A closer look at formulaic language: Prosodic characteristics of Swedish proverbs. Applied Linguistics. https://doi.org/10.1093/applin/amu078

Khatri, J., \& Laishram, L. (2013). Anthropological study of Manipuri proverbs. IMPACT: International Journal of Research in Humanities, Arts and Literature (IMPACT: IJRHAL), 1(3), 1-6. Retrieved from: http://citeseerx.ist.psu.edu/viewdoc/download?doi=10.1.1.671.1574\&rep=rep1\&type=pdf

Nabifar, N. (2013). A Comparative Study of English and Persian Proverbs on Basis of Cognitive Linguistics. Technical Journal of Engineering and Applied Sciences. Retrieved from: https://pdfs.semanticscholar.org/507f/1e953d0daf699c4a7597cf5f1d40d70b53ad.pdf

Van Lancker Sidtis, D., Choi, J.-H., Alken, A., \& Sidtis, J. J. (2015, October). Formulaic language in Parkinson's and Alzheimer's disease: Complementary effects of subcortical and cortical dysfunction. Journal of Speech Language and Hearing Research, 58(5), 1493-1507. https://doi.org/10.1044/2015_jslhr-1-14-0341

Singh, R. (2018). Derivational Grammar Model and Basket Verb: A Novel Approach to the Inflectional Phrase in the Generative Grammar and Cognitive Processing. English Linguistics Research, 7(2). https://doi.org/10.5430/elr.v7n2p9

Singh, R. (2018). A Cognitive Approach to the Semantics in the Sacred Context: Semantic and Symbolic Function of Sacred Words. English Linguistics Research, 7(3). https://doi.org/10.5430/elr.v7n3p1

Singh, R. (2018). Norwegian and Persian spatial prepositions: a novel comparative and syntactic approach to the spatial prepositions. KAAV international journal of English, literature, and linguistics, 5, 1-8. Retrieved from: http://www.kaavpublications.org/journals/journal-5/article/article-1788.pdf

Singh, R. (2018). Areas of errors and difficulty for Persian learners of Spanish caused by the sound system differences between Persian and Spanish: A phonetic approach to inter-lingual system. KAAV international journal of English, literature, and linguistics, 5, 1-8. Retrieved from: http://www.kaavpublications.org/journals/journal-5/abstract/abstract-1996.pdf

Singh, R. (2018). Mirroring Effects and the Water Code: A Cognitive-Semantic Approach to Natural Morphology in the Religious-Cultural Context. Journal of Literature, Languages and Linguistics, 46, 37-41. Retrieved from: https://www.researchgate.net/profile/Rajdeep_Singh22/publication/329922433_Mirroring_Effects_and_the_Wat er_Code_A_Cognitive-Semantic_Approach_to_Natural_Morphology_in_the_Religious-Cultural_Context/links/ 5c23ac09458515a4c7fad9aa/Mirroring-Effects-and-the-Water-Code-A-Cognitive-Semantic-Approach-to-Natura 1-Morphology-in-the-Religious-Cultural-Context.pdf

Singh, R. (2018). Russian and Negative Prefixing: A Cognitive-Semantic Approach to the Negative Adjective Prefixing in Russian, Spanish, Persian, and English. English Linguistics Research, 7(4). https://doi.org/10.5430/elr.v7n4p7

Singh, R. (2018). Auxiliary Verbs in Serbo-Croatian, French, Persian, Spanish and English: A Cognitive-Semantic Approach to the Auxiliary Verb Usage and Passive Voice. English Linguistics Research, 7(3). https://doi.org/10.5430/elr.v7n3p34

Singh, R. (2018). Language change and directionality: A novel model for language change in Persian and Iranian languages from the sociolinguistic perspective. KAAV International journal of English, Literature, and linguistics, 5, 1-8. Retrieved from: http://www.kaavpublications.org/journals/journal-5/article/article-1876.pdf 
Singh, R. (2018). Error Analysis of Persian Learners of Hausa Language: Cognitive Approach to Errors. Journal of Literature, Languages and Linguistics, 45, 10-15. Retrieved from: https://www.researchgate.net/profile/Rajdeep_Singh22/publication/329922323_Error_Analysis_of_Persian_Lea rners_of_Hausa_Language_Cognitive_Approach_to_Errors/links/5c23aac9458515a4c7fad97b/Error-Analysis-o f-Persian-Learners-of-Hausa-Language-Cognitive-Approach-to-Errors.pdf

Singh, R. (2018). Albanian World-View: Co-Locativity as the Schematic Meaning of Albanian Verbal Prefix Bashke-. English Linguistics Research, 7(4). https://doi.org/10.5430/elr.v7n4p28

Singh, R. (2018). Christian And Sikh Communities In Iran And Role Of Language Identity: A Comparative Approach To The Social-Linguistic Aspects Of The Christianity And Sikhism In The Middle East. Sikh Research Journal, 3(1). Retrieved from:

http://www.sikhfoundation.org/wp-content/uploads/2018/sikh-research-journal/Rajdeep_Singh-Sikh_Christian_ community_in_iran_and_the_language_identity_bahai.pdf 